\title{
Lactobacillus plantarum DR7 improved upper respiratory tract infections via enhancing immune and inflammatory parameters: A randomized, double-blind, placebo-controlled study
}

\author{
Hui-Xian Chong, ${ }^{1}$ Nur Asmaa' A. Yusoff, ${ }^{2}$ Yan-Yan Hor, ${ }^{1}$ Lee-Ching Lew, ${ }^{1}$ Mohamad Hafis Jaafar, ${ }^{1}$ \\ Sy-Bing Choi, ${ }^{3}$ Muhamad S. B. Yusoff, ${ }^{2}$ Normala Wahid, ${ }^{4}$ Mohammad Farris I. L. Abdullah, ${ }^{5}$ Norzila Zakaria, ${ }^{2}$ \\ Kee-Leong Ong, ${ }^{6}$ Yong-Ha Park, ${ }^{7 *}$ and Min-Tze Liong ${ }^{1 *}$ \\ ${ }^{1}$ School of Industrial Technology, Universiti Sains Malaysia, 11800 Penang, Malaysia \\ ${ }^{2}$ School of Medical Sciences, Universiti Sains Malaysia, 16150 Kubang Kerian, Malaysia \\ ${ }^{3}$ School of Data Sciences, Perdana University, 43400 Serdang, Malaysia \\ ${ }^{4}$ Community Health Center, Universiti Sains Malaysia, 11800 Penang, Malaysia \\ ${ }^{5}$ Advanced Medical and Dental Institute, Universiti Sains Malaysia, 13200 Bertam, Malaysia \\ ${ }^{6}$ Clinical Nutrition Intl (M) Sdn Bhd, 43200 Selangor, Malaysia \\ ${ }^{7}$ Department of Biotechnology, Yeungnam University, 712-749 Gyeongsan, Korea
}

\section{ABSTRACT}

The aims of this study were to investigate the effects of Lactobacillus plantarum DR7 isolated from bovine milk against upper respiratory tract infections (URTI) and elucidate the possible mechanisms underlying immunomodulatory properties. The DR7 strain (9 log $\mathrm{cfu} / \mathrm{d})$ was administered for $12 \mathrm{wk}$ in a randomized, double-blind, and placebo-controlled human study involving 109 adults (DR7, $\mathrm{n}=56$; placebo, $\mathrm{n}=53$ ). Subjects were assessed for health conditions monthly via questionnaires, and blood samples were evaluated for cytokine concentrations, peroxidation and oxidative stress, and gene expression in T cells and natural killer (NK) cells. The administration of DR7 reduced the duration of nasal symptoms (mean difference $5.09 \mathrm{~d} ; 95 \%$ CI: 0.42-9.75) and the frequency of URTI (mean difference 0.32 ; $95 \%$ CI: 0.01-0.63) after 12 and $4 \mathrm{wk}$, respectively, compared with the placebo. The DR7 treatment suppressed plasma proinflammatory cytokines (IFN- $\gamma$, TNF- $\alpha$ ) in middle-aged adults (30 to $60 \mathrm{yr}$ old), while enhancing anti-inflammatory cytokines (IL-4, IL-10) in young adults $(<30 \mathrm{yr}$ old $)$, accompanied by reduced plasma peroxidation and oxidative stress levels compared with the placebo. Young adults who received DR7 showed higher expression of plasma CD44 and CD117 by $4.50-$ and 2.22 -fold, respectively, compared with the placebo. Meanwhile, middle-aged adults

Received December 4, 2018.

Accepted February 12, 2019.

*Corresponding authors: peter@ynu.ac.kr and mintze.liong@usm .my showed lower expression of plasma CD4 and CD8 by 11.26- and 1.80-fold, respectively, compared with the placebo, indicating less T-cell activation. In contrast, both young and middle-aged adults who received DR7 showed enhanced presence of nonresting and mature NK cells compared with those who received the placebo. We postulate that DR7 alleviated the symptoms of URTI by improving inflammatory parameters and enhancing immunomodulatory properties.

Key words: Lactobacillus plantarum DR7, upper respiratory tract infection, mucosal integrity, $\mathrm{T}$ cells, natural killer cells

\section{INTRODUCTION}

In a hot and humid country such as Malaysia, respiratory illnesses occur throughout the year, with peaks during the dry season of midyear and wet season at year end. During the dry season, higher levels of airsuspended pollutants trigger inflammation processes in the airways, leading to increased mucosal permeability and consequent susceptibility to infection by pathogenic microorganisms. During the wet season, elevated humidity supports growth of mold and fungi and development of viruses, causing increased occurrence of coughs, allergic conditions, and airway infections (Lau et al., 2017). Upper respiratory tract infection (URTI) is a general term encompassing any infection that affects the upper respiratory system, including the common cold, laryngitis, sinusitis, and pharyngitis. These infections represent one of the most common health concerns affecting global communities. In the United States, adults have 2 to 3 incidences of URTI each year and children up to 5 times annually; however, over $20 \%$ of adults experience an URTI every 
4 wk (Bramley et al., 2002). Even healthy athletes are vulnerable; for example, over half of the professional Super 15 Rugby team players in New Zealand experienced URTI symptoms during a 4-wk training period (Haywood et al., 2014). Curative treatments are often not available for URTI because antibiotics are ineffective against viral infections; thus, URTI are mostly managed through relieving symptoms such as pain or fever. Because inflammatory and immune factors have been identified as crucial components underlying such symptoms, interventional remedies that target them have generated much interest amid initiatives to combat URTI.

Probiotics are "live microorganisms that exert health effects to the host if consumed in sufficient amounts" (FAO/WHO, 2006). Probiotic microorganisms include various genera, but species belonging to the genus $L a c$ tobacillus are among the most commonly administered, owing to their safety profiles and documented health benefits ranging from conventional gastrointestinal effects to potential alleviation of metabolic disorders (Ooi et al., 2010). Lactobacilli have also been widely reported to upregulate immunomodulatory parameters in the gut and gut-associated lymphoid tissues, modulate immune cells such as $\mathrm{T}$ cells that are present in the gut and other mucosal surfaces including the lungs, and reduce prescription of antibiotics and absenteeism due to respiratory viral infections (Ahanchian et al., 2012; Lehtoranta et al., 2014; Hor et al., 2018). In summary, lactobacilli probiotics may be a promising natural approach to prevent or treat URTI.

Lactobacillus plantarum DR7, a bovine milk isolate from Penang, Malaysia, has been found to activate and phosphorylate AMP protein kinase (AMPK; Lew et al., 2011). This enzyme, an energy sensor that plays a role in sustaining cellular energy levels, has been recognized as a potential therapeutic target for metabolic diseases and control of glucose and lipid metabolism. Recently, the activation of AMPK via phosphorylation was found to play a role in reducing influenza viral infections via activation of macrophages (Uematsu et al., 2016), indicating the importance of immunomodulatory functions during viral attacks. We hypothesized that the AMPK activation potential of DR7 may exert a certain level of immunomodulatory protection against URTI. Most research has emphasized strain and host dependencies because the targeted effects of most lactobacilli against URTI remain unknown, so we sought answers regarding efficacy and mechanisms in a human intervention study. In this study, we first explored the probiotic properties of DR7 before assessing its efficacy in combating URTI in adults, primarily via anti-inflammatory and immunomodulatory properties.

\section{MATERIALS AND METHODS}

\section{Probiotic Properties}

Stock cultures of DR7 were prepared, preserved, and activated before use as previously described (Lew et al., 2013). Probiotic properties that were evaluated included the ability to adhere to mucin (Tham et al., 2012), resistance under gastric and intestinal fluid conditions (Lew et al., 2011), antioxidant potentials (Benzie and Strain, 1996), antibiotic resistance as defined by the European Food Safety Authority (EFSA; Klare et al., 2007), and carbon utilization ability using the API-50 CHL kit (bioMérieux, Cambridge, MA) per the manufacturer's instructions. The DR7 isolate was also evaluated for its ability to use prebiotics such as fructooligosaccharide, galactooligosaccharide, and inulin (Fuji Neihon Seito, Tokyo, Japan). A medium similar to de Man, Rogosa, Sharpe was prepared, with glucose $(2 \% \mathrm{wt} / \mathrm{vol}$ ) being substituted with $2 \%$ (wt/ vol) of the individual prebiotics. The de Man, Rogosa, Sharpe medium was used as a positive control. Growth of DR7 (optical density at $600 \mathrm{~nm}, 37^{\circ} \mathrm{C}$ ) was recorded every $3 \mathrm{~h}$ for $24 \mathrm{~h}$. Antimicrobial activity of cell-free supernatant from DR7 against respiratory-related pathogens was performed using Staphylococcus aureus ATCC 6538P, Streptococcus mutans KCTC 5244, and clinical isolates of Streptococcus pneumonia and Streptococcus pyogenes in 96-well plates. Pathogens growing without any treatment served as negative controls, while amoxicillin $(1.5 \mu \mathrm{g} / \mathrm{mL})$ and vancomycin $(2 \mu \mathrm{g} / \mathrm{mL})$ were used as positive controls (Hor and Liong, 2014). Streptococcus mutans and Streptococcus pneumoniae were grown and maintained in brain heart infusion broth (HiMedia, Mumbai, India), and Staph. aureus was grown in trypticase soy broth (HiMedia) at $37^{\circ} \mathrm{C}$. Growth was recorded at 2- or 4-h intervals until the negative controls achieved stationary phase. Cytotoxicity was determined using a human liver hepatocellular cell line (HepG2) treated with different concentrations of cell-free supernatant from DR7 for $24 \mathrm{~h}$ at $37^{\circ} \mathrm{C}$, $5 \% \mathrm{CO}_{2}$ before determination of viability via the MTT assay (Tuo et al., 2010).

\section{Lactobacillus plantarum DR7 and Placebo Products}

DR7 and placebo products were manufactured by GN Pharmaceuticals Sdn. Bhd. (Selangor, Malaysia). Products did not contain any porcine or bovine ingredients; they were manufactured under GMP and certified halal by JAKIM (Department of Islamic Development Malaysia). The probiotic product contained $1 \times 10^{9} \mathrm{cfu} /$ sachet of DR7 and maltodextrin as excipient (95\%), 
while the placebo contained only maltodextrin (100\%). Each dose was $2 \mathrm{~g}$ of a light yellow powder supplied in an aluminum sachet, and all products were identical in taste. Sachets were stored away from direct sunlight and below $30^{\circ} \mathrm{C}$.

\section{Selection of Subjects}

Subjects were selected as previously described (Hor et al., 2018). Briefly, subjects were recruited from Penang and Kubang Kerian, Malaysia, and screened based on inclusion and exclusion criteria. Inclusion criteria required male and female participants to be aged 18 to $60 \mathrm{yr}$ old and willing to commit to the study for the duration of the experiment. Exclusion criteria included type 1 diabetes, long-term medication due to severe illness, HIV/AIDS, and glucose-6-phosphate dehydrogenase deficiency. Individuals who, in opinion of the investigator, seemed unlikely to complete the trial were also excluded. Written informed consent was obtained from all subjects before the start of the study.

\section{Study Protocol}

This study was conducted according to the guidelines established in the Declaration of Helsinki. All procedures involving human subjects were approved by the JEPeM-USM Review Panel on Clinical Studies of Universiti Sains Malaysia. The protocol of Hor et al. (2018) was applied in this double-blind, randomized, and placebo-controlled study, with some modifications involving sample size determination. The sample size was calculated for a parallel group study design involving one prevention arm and one placebo arm and was based on power design analysis. A total of 124 subjects were needed for this study, comprising 62 subjects in each group (DR7 and placebo) and an additional 10\% to account for dropouts. This calculation was based on the need for a continuous response variable from independent control and experimental subjects, with a ratio of control to subject fixed at 1:1, probability (power) of 0.9 , and type I error probability associated with testing the null hypothesis of 0.05 . Previous data have shown that for an intervention using probiotics against reducing duration of illness arising from pulmonary diseases and symptoms, a standard deviation of $1.7 \mathrm{~d}$ within group was observed, accompanied by a reduction of $1 \mathrm{~d}$ between treatment and placebo groups (Tiollier et al., 2007).

\section{Analyses}

Two types of questionnaires were used in this study: (i) basic demographic questionnaire (baseline; $0 \mathrm{wk}$ ), and (ii) health condition questionnaire every 4 wk to record occurrences of upper respiratory illnesses (duration of respiratory-related illness, number of symptoms, number of illness episodes). All questionnaires were validated and available in 3 languages; namely, English, Malay, and Chinese (Lau et al., 2018a,b).

Blood samples were collected (baseline and wk 12) and analyzed as previously described (Hor et al., 2018). Briefly, concentrations of cytokines in plasma were determined using ELISA kits (Immundiagnostik, Bensheim, Germany) following the manufacturer's instructions, while whole blood was analyzed for complete blood count (Gribbles Pathology, Penang, Malaysia). Plasma membrane and hemolysate fractions of red blood cells (RBC) samples were evaluated for peroxidation of lipids and antioxidant potentials as previously described (Hor et al., 2018), with the hemolysates and RBC membranes being obtained according to the protocol of Ooi et al. (2010). Gene expression of whole blood was performed as previously described (Hor et al., 2018), using the primer sequences shown in Table 1. Data were calculated using the comparative $\mathrm{Ct}(\Delta \mathrm{Ct})$ method for relative quantification, while the $18 \mathrm{~S}$ rRNA gene was used as a housekeeping gene for normalization of data.

\section{Statistical Analyses}

Data were analyzed using SPSS version 20.0 (SPSS Inc., Chicago, IL). The primary hypothesis of this study involved differential efficacy between the 2 treatment groups of DR7 and placebo. The score differences between different time points were examined using 1-sample $t$-test in which the mean of the differences had a hypothesized value of zero. Differences between DR7 and placebo groups were compared using the independent $t$-test. Comparisons between treatment groups as a measure of time were assessed using between-group repeated measures ANOVA (general linear model) with treatment groups and time as main effects and inclusion of a group-by-time interaction term. Because our data had a skewed distribution and were nonparametric, the associations between variables in different groups were evaluated using Spearman rank correlations (rho) as the correlation coefficient. All tests were 2 sided with $P$ $<0.05$ considered statistically significant.

\section{RESULTS}

\section{Probiotic Properties}

Cells of DR7 showed an ability to adhere to mucin; of the $6.7 \times 10^{10} \mathrm{cfu} / \mathrm{mL}$ cells inoculated, $4.0 \times 10^{9} \mathrm{cfu} /$ $\mathrm{mL}$ cells adhered to mucin. The DR7 isolate also toler- 
Table 1. List of primer sequences used for quantitative real-time PCR

\begin{tabular}{|c|c|c|c|}
\hline Target gene & Primer sequence $\left(5^{\prime}-3^{\prime}\right)^{1}$ & $\mathrm{~T}_{\mathrm{A}}^{2}\left({ }^{\circ} \mathrm{C}\right)$ & Reference \\
\hline$C D_{4}$ & F: AGAGCCTGACCCTGACCTTG & 55 & Huang et al. (2006) \\
\hline$C D 8$ & $\begin{array}{l}\text { F: CCGGCACCAATTCCTGTTCT } \\
\text { R: CCTCCGTCTCCTTTAGGCTG }\end{array}$ & 55 & NG_011608 ${ }^{3}$ \\
\hline$C D 44$ & $\begin{array}{l}\text { F: CCTGCAGGTATGGGTTCATAG } \\
\text { R: GGTGTTGGATGTGAGGATGT }\end{array}$ & 60 & NM_000610 3 \\
\hline$C D 56$ & $\begin{array}{l}\text { F: GATGCGACCATCCACCTCAA } \\
\text { R: TCTCCGGAGGCTTCACAGGTA }\end{array}$ & 60 & Kashiwagi et al. (2012) \\
\hline$C D 94$ & $\begin{array}{l}\text { F: ACCCATTTTTCTTGGCAAGAACAGCA } \\
\text { R: TTGTTGAAAAATTCTTTTACTAAACT }\end{array}$ & 60 & Lin et al. (2003) \\
\hline NKрзо & $\begin{array}{l}\text { F: CATGGTCCATCCAGGATCC } \\
\text { R: GTTCCATTCCTCACCTCCTTC }\end{array}$ & 60 & Shemesh et al. (2016) \\
\hline
\end{tabular}

${ }^{1} \mathrm{~F}=$ forward primer; $\mathrm{R}=$ reverse primer.

${ }^{2}$ Annealing temperature.

${ }^{3}$ National Center for Biotechnology Information (NCBI) accession number.

ated simulated gastric acid conditions, with observed growth of $2.1 \times 10^{8} \mathrm{cfu} / \mathrm{mL}$ at $\mathrm{pH} 3.0$ compared with $8.1 \times 10^{8} \mathrm{cfu} / \mathrm{mL}$ at $\mathrm{pH} 7.2$. The DR7 isolate tolerated intestinal bile with growth being maintained at $47.55 \%$ in a bile concentration of $0.3 \%$. Cell-free supernatant of DR7 exhibited an antioxidant potential that was $10.72 \%$ higher than the level of standard antioxidant Trolox $(P$ $<0.05)$. The assessment of carbon utilization ability revealed that DR7 used sugars such as L-arabinose, Dribose, D-galactose, D-glucose, D-fructose, D-mannose, D-mannitol, D-sorbitol, methyl- $\alpha$-D-mannopytanoside, $\mathrm{N}$-acetylglucosamine, amygdalin, arbutin, esculin ferric citrate, salicin, D-cellobiose, D-maltose, D-lactose, D-melibiose, D-saccharose, D-trehalose, D-melezitose, D-raffinose, gentiobiose, D-turanose, and potassium gluconate. The DR7 isolate adhered to nonantibiotic resistance standards with cutoff values lower than those required by EFSA for antibiotics such as gentamicin, kanamycin, tetracycline, erythromycin, clindamycin, and ampicillin, while exhibiting a cutoff value similar to that required by EFSA for chloramphenicol $(8 \mathrm{mg} / \mathrm{L})$. The DR7 isolate used shorter chained galactose-based oligosaccharide prebiotics such as galactooligosaccharide better than fructose-based oligosaccharide prebiotics such as fructooligosaccharide and did not thrive with longer-chained oligosaccharide prebiotics such as inulin (Supplemental Figure S1A; https://doi.org/10 $.3168 /$ jds.2018-16103). In vitro antimicrobial assays showed that the cell-free supernatant of DR7 exhibited inhibitory activities against pathogens related to respiratory diseases such as Staph. aureus, Strep. pneumoniae, Strep. pyogenes, and Strep. mutans (Supplemental
Figure 1B-E; https://doi.org/10.3168/jds.2018-16103). The DR7 isolate showed similar antimicrobial effects as amoxicillin against Staph. aureus and vancomycin against Strep. pyogenes, while outperforming vancomycin against Strep. pneumoniae. The cell-free supernatant of DR7 did not exert toxic effects on HepG2 cells, with viability exceeding $80 \%$ for all concentrations of cell-free supernatant studied, except for undiluted cell-free supernatant for which a viability of $79.6 \%$ was observed (Supplemental Figure 1F; https://doi.org/ 10.3168/jds.2018-16103). In general, DR7 fulfilled the recommended probiotic criteria and could be suitable for food or health applications.

\section{Human Study}

Baseline and Complete Blood Count Characteristics. Of the recruited 124 subjects, 5 subjects dropped out during the 12 -wk period, while 10 subjects did not fully comply with answering questionnaires or providing blood samples, yielding 109 subjects after the 12-wk study (Figure 1; DR7, $\mathrm{n}=56$; placebo, $\mathrm{n}=53$ ). Insignificant differences were observed in most of the general characteristics and complete blood count parameters of DR7 and placebo subjects for both young adults (age $<30 \mathrm{yr}$ old) and adults (30 to $60 \mathrm{yr}$ old) and the overall populations over time (Table 2). An exception was mean corpuscular hemoglobin concentration, for which placebo subjects had lower levels than DR7 at baseline, while placebo subjects had lower levels of eosinophils than the DR7 subjects after 12 wk. In general, neither the placebo nor the DR7 group exhibited 


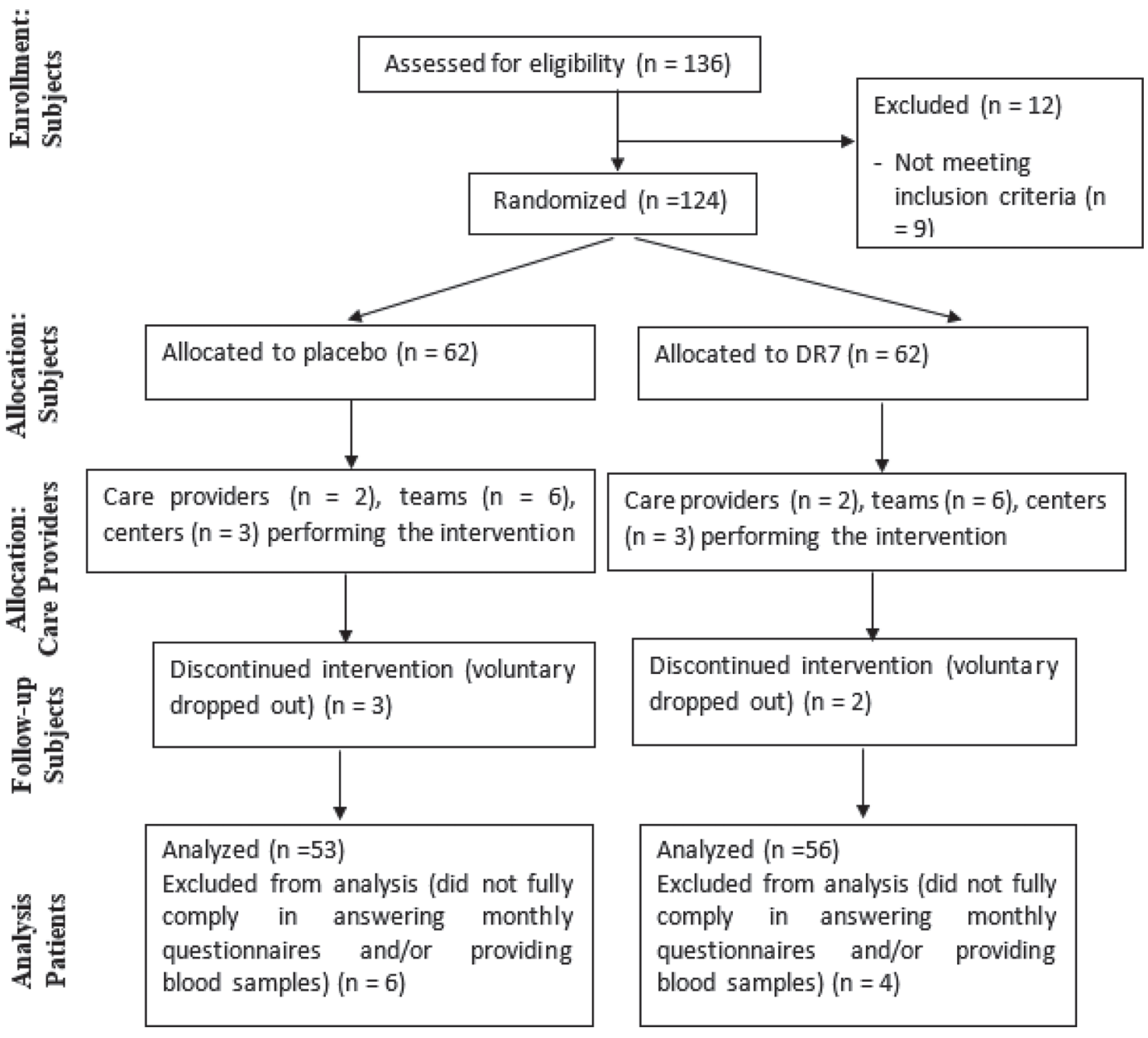

Figure 1. Flowchart detailing participants' recruitment, randomization, and allocation. DR7 = Lactobacillus plantarum DR7.

significant changes of complete blood count parameters during the 12-wk study period.

Upper Respiratory Infections. The administration of DR7 marginally reduced the duration for nasal $(P=0.093)$, pharyngeal $(P=0.082)$, and general flu symptoms $(P=0.066)$ in young adults compared with the placebo (Figure $2 \mathrm{~A}$ ) over $12 \mathrm{wk}$. The DR7 isolate significantly reduced the duration of nasal symptoms (mean difference $4.82 \mathrm{~d} ; 95 \%$ CI: 0.44-9.19; $P=0.032$ ) in middle-aged adults compared with the placebo, while it marginally reduced the duration of general flu symptoms $(P=00.062)$ and frequency of URTI $(P=$ 0.080 ; Figure $2 \mathrm{~B}$ ) during the 12 -wk study period. In a comparison of all subjects, DR7 reduced the duration of nasal symptoms (mean difference $5.09 ; 95 \%$ CI: $0.42-9.75 ; P=0.033$ ) and frequency of URTI (mean difference $0.32 ; 95 \%$ CI: $0.01-0.63 ; P=0.042$ ) after 12 and $4 \mathrm{wk}$, respectively, compared with the placebo, while it marginally reduced the duration of pharyngeal
$(P=0.051)$ and general flu symptoms $(P=0.051)$ compared with the placebo over 12 wk (Figure 2C). In general, DR7 alleviated URTI symptoms better than the placebo over 12 wk, typically against nasal symptoms.

Plasma Cytokines. Plasma anti-inflammatory cytokines such as IL-4 (mean difference -11.45; $95 \%$ CI: -21.37 to $-1.52 ; P=0.025$ ) and IL-10 (mean difference $-6.65 ; 95 \%$ CI: -11.22 to $-2.08 ; P=0.005$ ) were increased in young adults upon administration of DR7 compared with placebo over 12 wk (Figure 3A,B), while insignificant differences were observed in middleaged adults. In a comparison of all subjects, the administration of DR7 decreased plasma proinflammatory cytokines such as TNF- $\alpha$ (mean difference $0.82 ; 95 \%$ CI: $0.03-1.61 ; P=0.042$ ) and IFN- $\gamma$ (mean difference 5.97; 95\% CI: 2.92-9.03; $P<0.001$ ), while increasing plasma anti-inflammatory cytokines such as IL-4 (mean difference $-7.93 ; 95 \%$ CI: -15.23 to $-0.63 ; P=0.034$ ) 


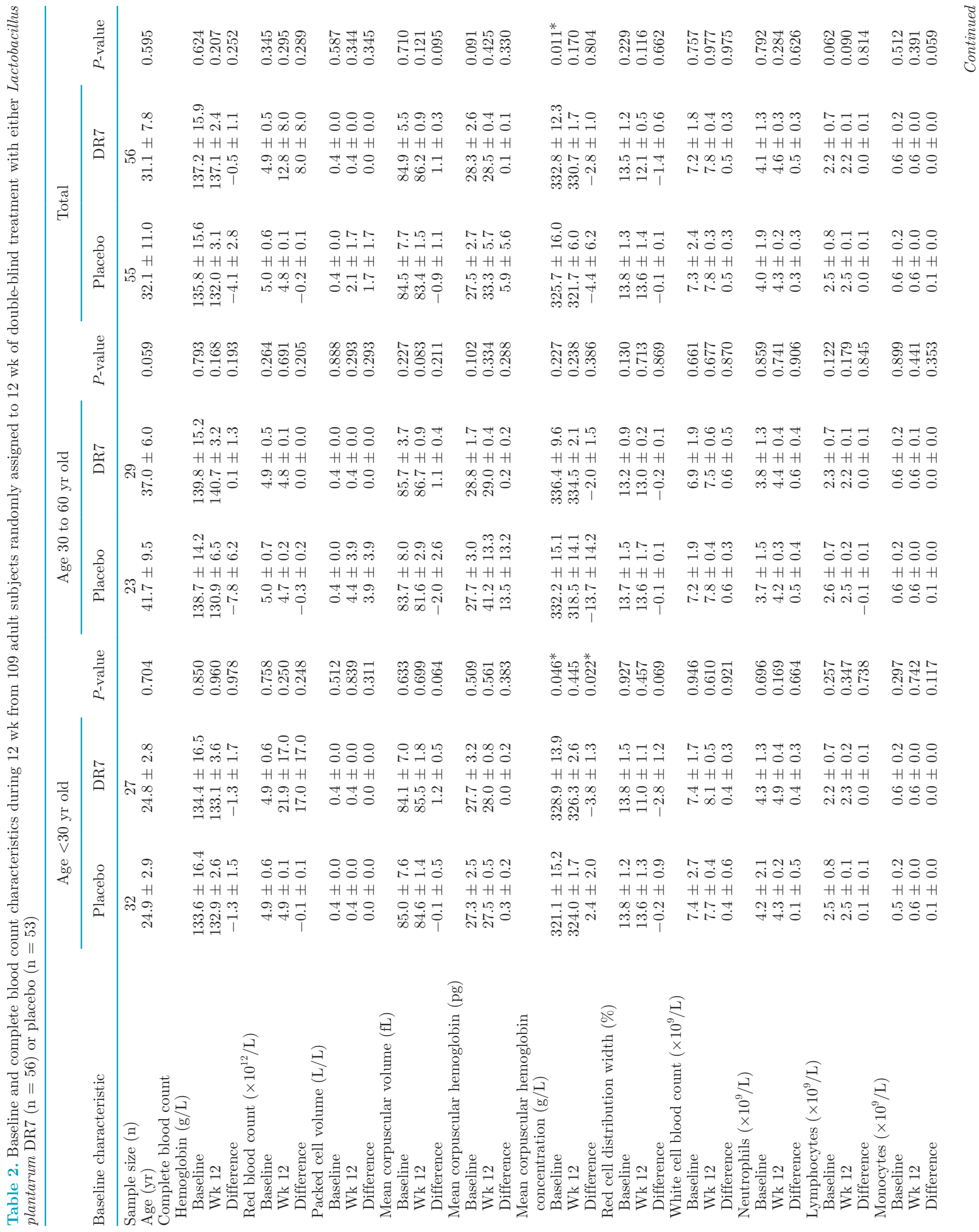


and IL-10 (mean difference $-5.13 ; 95 \%$ CI: -8.75 to $-1.52 ; P=0.006$ ) compared with placebo (Figure 3C) over 12 wk. In general, DR7 alleviated inflammatory parameters better than the placebo over $12 \mathrm{wk}$. Plasma proinflammatory cytokines such as IFN- $\gamma$ (mean difference $7.14 ; 95 \%$ CI: $3.36-10.92 ; P<0.001)$, TNF- $\alpha$
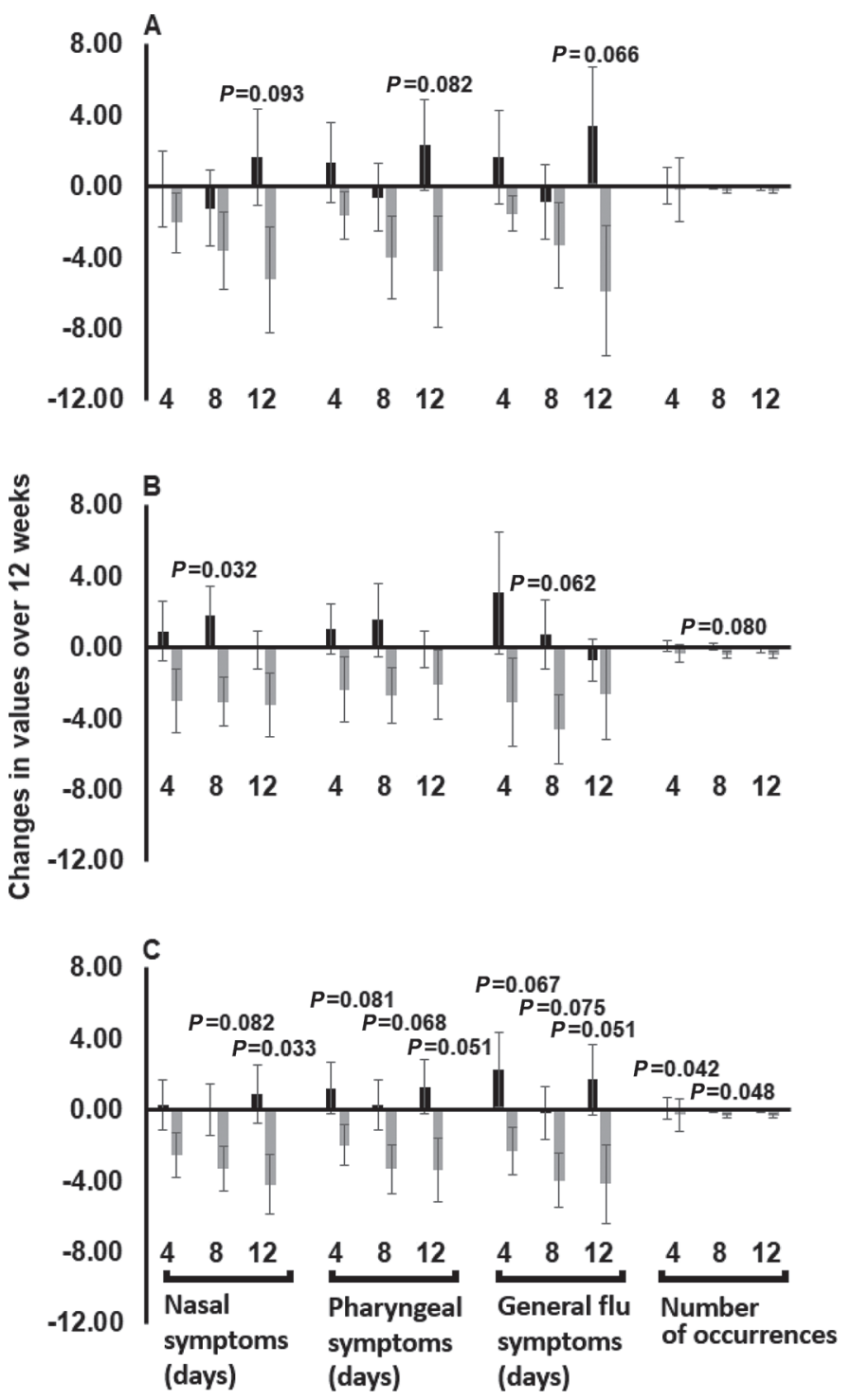

Figure 2. Changes in the number of days and occurrences of upper respiratory tract infections measured at wk 4, 8, and 12 compared with wk 0 , during a 12 -wk administration of probiotic Lactobacillus plantarum DR7 (gray) or placebo (black) in (A) young adults $(<30$ yr old), (B) middle-aged adults (30-60 yr old) (nasal symptoms: W, $P=0.649 ; \mathrm{T}, P=0.043 ; \mathrm{T} \times \mathrm{W}, P=0.741)$, and $(\mathrm{C})$ all subjects (nasal symptoms: $\mathrm{W}, P=0.831 ; \mathrm{T}, P=0.027 ; \mathrm{T} \times \mathrm{W}, P=0.510$; number of occurrences: $\mathrm{W}, P=0.462 ; \mathrm{T}, P=0.029$; $\mathrm{T} \times \mathrm{W}, P=$ $0.860)$. $P$-values indicate differences between treatment groups at individual time points. Repeated-measures ANOVA provided statistical significance on W: effect of weeks; T: effect of treatment groups DR7 and placebo; $\mathrm{T} \times \mathrm{W}$ : interaction between weeks and treatment. Total $\mathrm{n}=109 ; \mathrm{DR} 7, \mathrm{n}=56$, placebo, $\mathrm{n}=53$. Results are expressed as mean \pm SEM. 


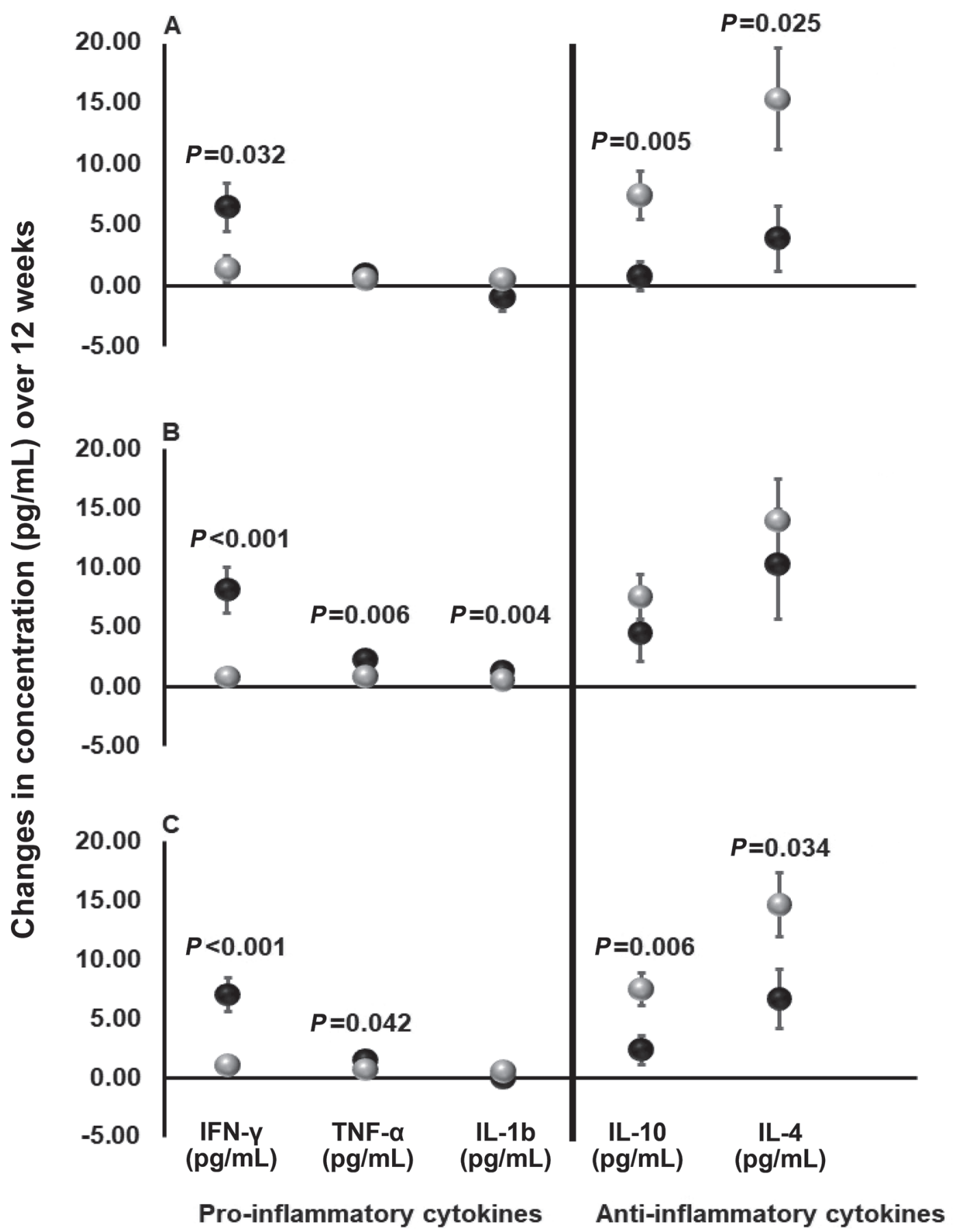

Figure 3. Changes in levels of plasma cytokines (pg/mL; IL-1 $\beta$, IL-4, and IL-10, tumor necrosis factor (TNF)- $\alpha$, IFN- $\gamma$ ) between wk 0 and 12 upon administration of Lactobacillus plantarum DR7 (gray) or placebo (black) in (A) young adults ( $<30$ yr old), (B) middle-aged adults (30-60 yr old), and (C) all subjects. Total $\mathrm{n}=109 ; \mathrm{DR} 7, \mathrm{n}=56$; placebo, $\mathrm{n}=53$. $P$-values indicate differences between treatment groups. Results are expressed as mean \pm SEM.

(mean difference $1.46 ; 95 \%$ CI: $0.43-2.49 ; P=0.006$ ) and IL-1 $\beta$ (mean difference $0.75 ; 95 \%$ CI: $0.24-1.26$; $P=0.004)$ were reduced in middle-aged adults upon administration of DR7 compared with placebo over 12 wk, while DR7 only reduced IFN- $\gamma$ (mean difference
5.06; 95\% CI: $0.45-9.67 ; P=0.032)$ in young adults compared with the placebo (Figure 4A,B).

Lipid Peroxidation. Although the administration of DR7 did not affect antioxidant potentials in plasma, $\mathrm{RBC}$ membrane, or hemolysate of young adults relative 

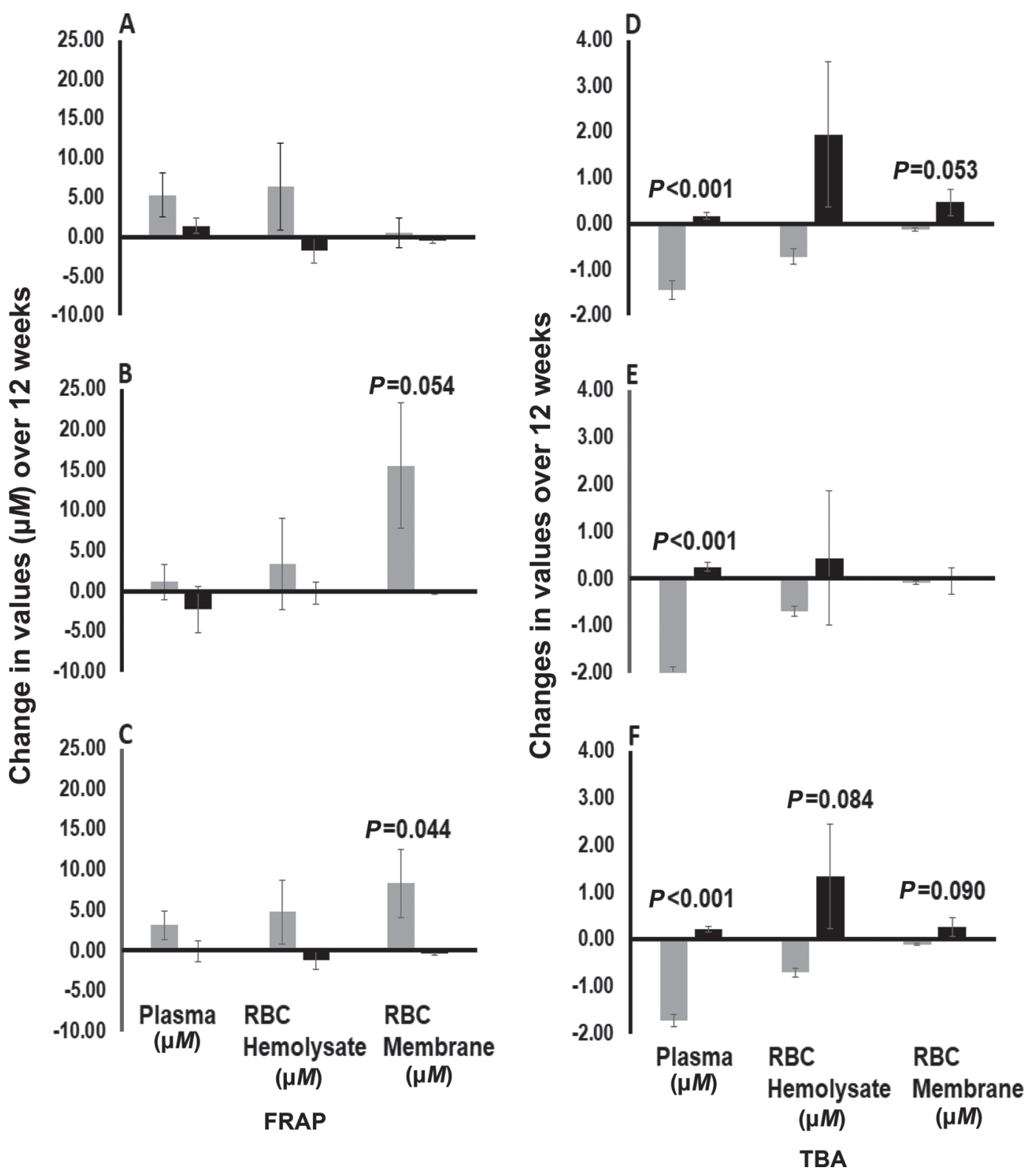

Figure 4. Changes in levels of ferric-reducing antioxidant potential (FRAP) and thiobarbituric acid (TBA) in plasma and red blood cell (RBC) membrane and hemolysate $(\mu M)$ between wk 0 and 12 upon administration of probiotic Lactobacillus plantarum DR7 (gray) or placebo (black) in (A, D) young adults ( $<30 \mathrm{yr}$ old), (B, E) middle-aged adults (30-60 yr old), and (C, F) all subjects. $P$-values indicate differences between treatment groups. Total $\mathrm{n}=109$; $\mathrm{DR} 7, \mathrm{n}=56$; placebo, $\mathrm{n}=53$. Results are expressed as mean \pm SEM.

to the placebo (Figure $4 \mathrm{~A}$ ), it marginally increased the antioxidant potential of RBC membranes in middleaged adults $(P=0.054$, Figure $4 \mathrm{~B})$ and significantly increased this factor in all subjects over 12 wk compared with placebo (mean difference $4.21 ; 95 \%$ CI: -17.11 to $-0.24 ; P=0.044$, Figure $4 \mathrm{C}$ ). The administration of DR7 also decreased the concentration of malondialdehyde as determined by thiobarbituric acid (TBA) in the plasma of young adults (Figure 4D, mean difference
1.61; 95\% CI: $1.21-2.02 ; P<0.001)$, middle-aged adults (Figure 4E, mean difference 2.25; 95\% CI: $1.88-2.62 ; P$ $<0.001$ ), and all subjects (Figure $4 \mathrm{~F}$, mean difference 1.94; 95\% CI: $1.65-2.21 ; P<0.001)$ compared with the placebo, which showed an increase over $12 \mathrm{wk}$. A marginal decrease in levels of TBA was also observed in the RBC membrane of young adults $(P=0.053)$ and all subjects $(P=0.090)$ and in the RBC hemolysate of all subjects $(P=0.084)$ upon administration of DR7 

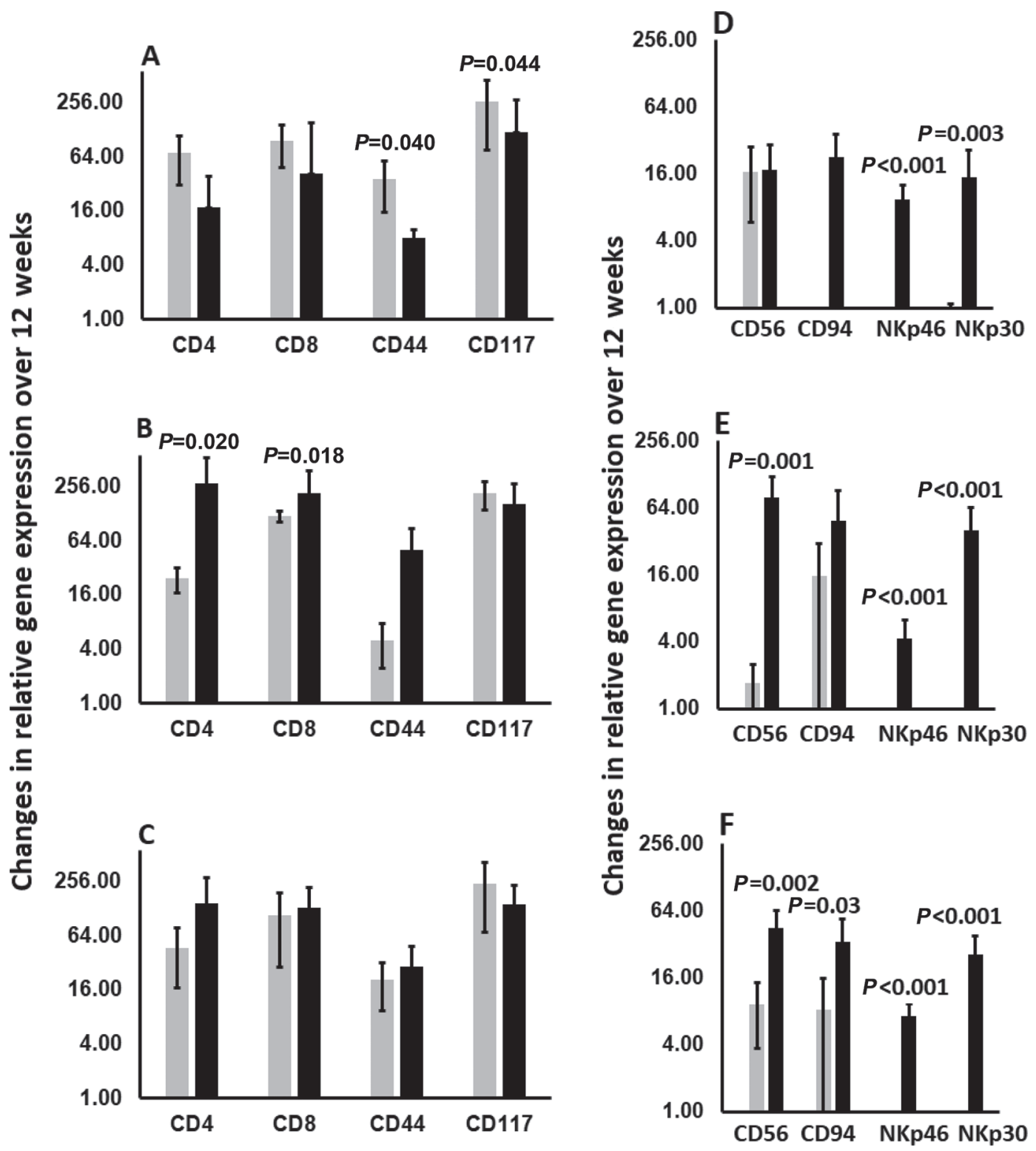

Figure 5. Changes in relative gene expressions of plasma genes for T cells (CD4, CD8, CD44, CD117) and natural killer (NK) cells (CD34, CD56, CD94, NKp46, NKp30) between wk 0 and 12 upon administration of probiotic Lactobacillus plantarum DR7 (gray) or placebo (black) in (A, D) young adults (<30 yr old), (B, E) adults (30-60 yr old), and (C, F) all subjects. Total $\mathrm{n}=109 ; \mathrm{DR} 7, \mathrm{n}=56 ; \mathrm{placebo}, \mathrm{n}=53$. P-values indicate differences between treatment groups. Results are expressed as mean \pm SEM.

compared with placebo over 12 wk (Figures 4D, F). In general, DR7 reduced the oxidation of the RBC membrane better than the placebo over 12 wk.

Plasma Immunity Parameters. The administration of DR7 upregulated the expression of plasma genes for CD44 (mean difference $-1.89 ; 95 \%$ CI: -3.69 to $-0.09 ; P=0.040$ ) and CD117 (mean difference -2.74 ; $95 \% \mathrm{CI}:-5.41$ to $-0.07 ; P=0.044)$ in young adults over 12 wk compared with the placebo (Figure 5A), while it downregulated the expression of plasma genes for CD4 (mean difference 3.84; 95\% CI: 0.62-7.07; $P=0.020$ ) and CD8 (mean difference 3.91; 95\% CI: 0.69-7.13; $P=$ 0.018 ) in middle-aged adults over $12 \mathrm{wk}$ compared with the placebo (Figure 5B). In a comparison of all subjects, insignificant differences were observed for these factors between subjects receiving DR7 and placebo (Figure 5C). The administration of DR7 downregulated the expression of plasma genes for NKp46 (mean difference $8.21 ; 95 \%$ CI: $5.29-11.13 ; P<0.001)$ and NKp30 (mean difference $4.52 ; 95 \%$ CI: $1.93-7.12 ; P=0.003$ ) in young adults (Figure 5D); CD56 (mean difference 5.17; 95\% CI: $2.24-8.10 ; P=0.001$ ), NKp46 (mean differ- 
ence 8.79; 95\% CI: 5.53-12.07; $P<0.001)$, and NKp30 (mean difference 8.31; 95\% CI: 5.06-11.57; $P<0.001$ ) in middle-aged adults (Figure 5E); and CD56 (mean difference $4.13 ; 95 \%$ CI: 1.85 to $6.41 ; P=0.002$ ), CD94 (mean difference 3.16; 95\% CI: 1.11-5.21; $P=0.003$ ), NKp46 (mean difference 8.51; 95\% CI: 6.36-10.66; $P$
$<0.001$ ), and NKp30 (mean difference $6.41 ; 95 \%$ CI: 4.33 to $8.48 ; P<0.001$ ) in all subjects (Figure $5 \mathrm{~F}$ ) over 12 wk compared with the placebo. In general, the administration of DR7 led to less activation of T cells compared with the control over $12 \mathrm{wk}$, accompanied by more nonresting and mature natural killer (NK) cells.
(A)

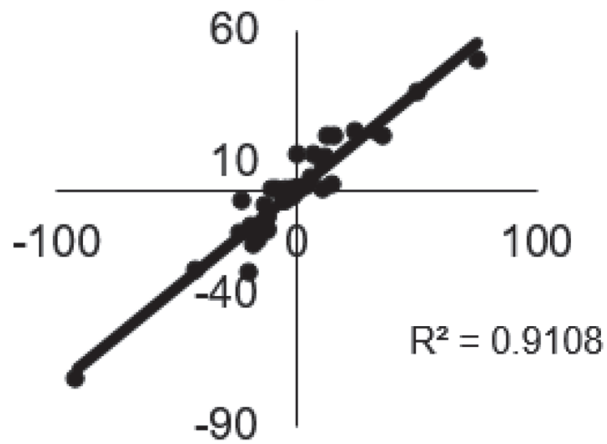

(D)

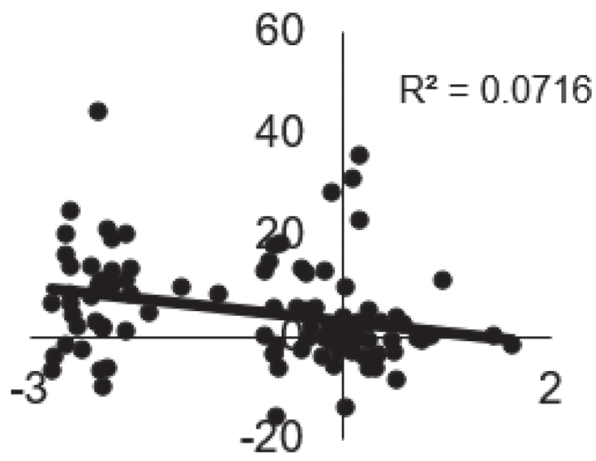

(B)

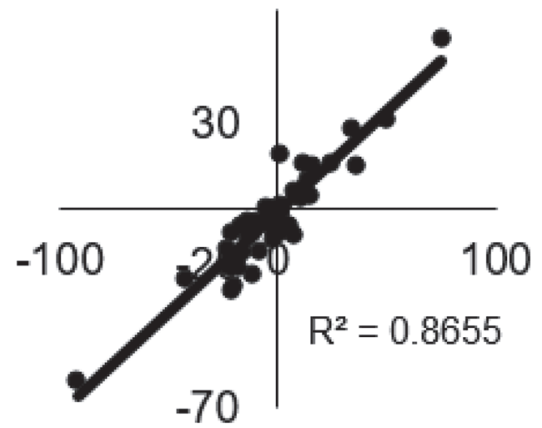

(E)

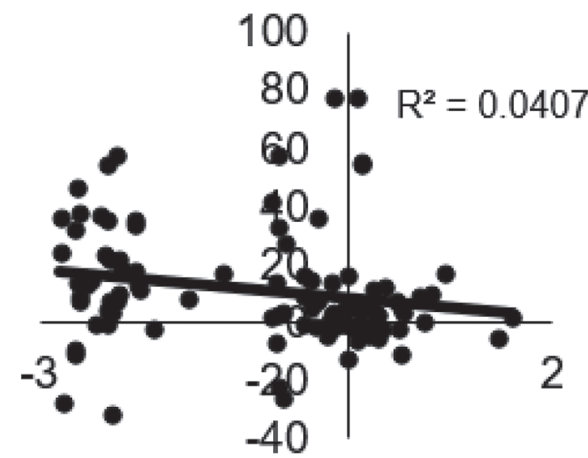

(C)

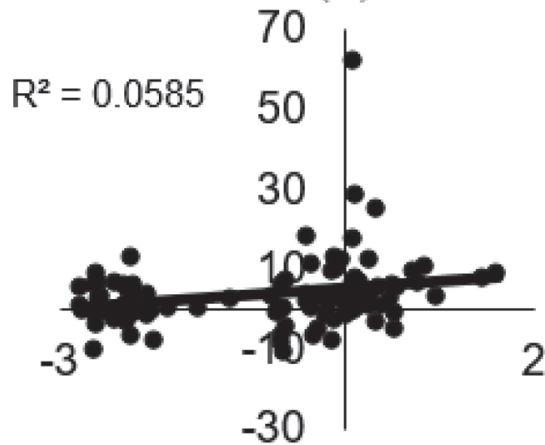

(F)

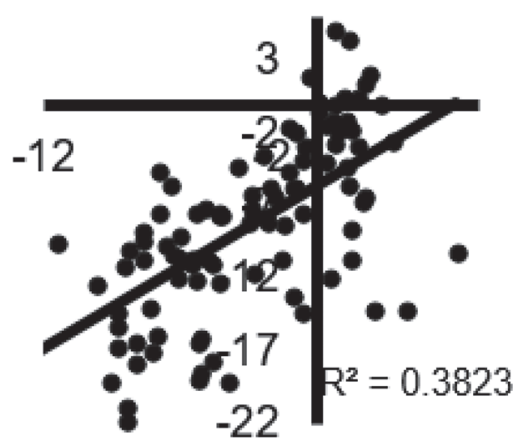

(G)

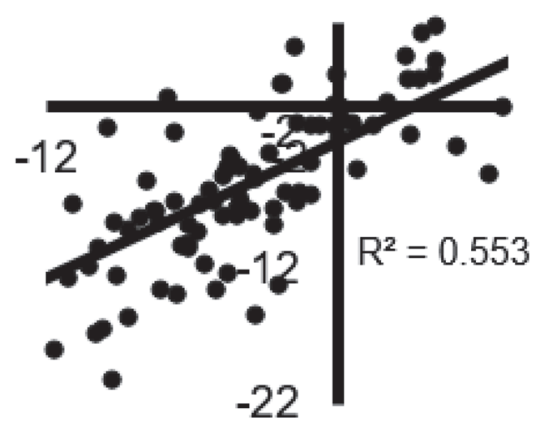

Figure 6. Spearman correlation charts for changes of (A) pharyngeal; and (B) nasal symptoms against general flu symptoms; plasma IFN- $\gamma$ (C), IL-10 (D), and IL-4 (E) against plasma thiobarbituric acid; and plasma expression of genes for CD117 (F) and CD8 (G) against CD44 for all subjects (total $\mathrm{n}=109$; Lactobacillus plantarum $\mathrm{DR} 7, \mathrm{n}=56$; placebo, $\mathrm{n}=53$ ) over 12 wk. 


\section{Correlation Analyses}

Both pharyngeal and nasal symptoms showed high correlations with general flu symptoms (Figure 6A, B). Interferon- $\gamma$ showed a marginal positive correlation with plasma TBA levels (Figure 6C), while IL-10 and IL-4 showed a marginal negative correlation with plasma TBA levels (Figure 6D, E). Plasma expression of genes for CD117 showed a moderate correlation with CD44 (Figure 6F), while CD8 showed a high correlation with CD44 (Figure 6G).

\section{DISCUSSION}

Putative probiotic strains are required to fulfill probiotic criteria before use as food or health ingredients. Our data showed that DR7 met selection characteristics for probiotic microorganisms (FAO/WHO 2001) and also exhibited antimicrobial effects against pathogens related to respiratory tract infections. Staphylococcus aureus is a pathogen commonly associated with both URTI and lower respiratory tract infections (LRTI), with clinical strains having been isolated from the nasopharynx (Pettigrew et al., 2008) and trachea (Lacoma et al., 2015). Streptococcus pneumoniae primarily causes LRTI such as pneumonia (Lacoma et al., 2015), while Strep. pyogenes is a group-A streptococcus, commonly isolated from patients with URTI, that causes pharyngitis, tonsillitis, and asthma (Juhn et al., 2012). Streptococcus mutans primarily causes dental caries, but it has also been isolated from microbial biofilms on the inner luminal surface of endotracheal tubes removed from intensive care unit patients with LRTI. This finding may be attributed to the organism's ability to form biofilms that are conducive to colonization by respiratory pathogens because the presence of Strep. mutans has been reported to synergistically increase the growth of Staph. aureus (Cairns et al., 2011). In addition, DR7 did not demonstrate toxicity in HepG2 cells. HepG2 cells have been widely used as a model to evaluate cytotoxicity of a wide variety of chemicals and drugs owing to their susceptibility to DNA damage and apoptosis, and to evaluate genotoxicity because of their ability to express metabolic enzymes that activate DNA-reactive carcinogens (Carney and Settivari, 2013). The safety of DR7 was also shown by the insignificant changes of most complete blood count parameters over $12 \mathrm{wk}$.

Increased susceptibility to respiratory tract infections is commonly associated with decreased host immunity. Malaysia has hot and humid weather typical of a tropical climate, with increasing prevalence of respiratory tract infections, typically URTI, during the hot season (midyear) and wet season (year end). One of the primary evaluations using Lactobacillus to enhance immu- nity centers on the prevention or treatment of URTI, with human subjects being evaluated for occurrences of sickness. Upper respiratory tract infection is one of the major reasons cited for absences from work and school and decreased workforce productivity. In Malaysia, URTI represent $16.5 \%$ and $21.2 \%$ of the diseases diagnosed in public and private health clinics, respectively (Lim et al., 2013).

As global populations age, nutrition and prevention of diseases and health disorders are crucial for creating healthier communities. As the human life span has increased, with mortality extending beyond $85 \mathrm{yr}$ in developed countries, the period of adulthood has also been extended. Because most of the working years occur during adulthood, we targeted a healthier adult population that would subsequently form a healthier aging population. In the context of nutrition and diet, little information is available on the effects of probiotic interventions on the health of young adults $(<30 \mathrm{yr}$ old) because most studies have focused on middle-aged adults (31-60 yr old). We thus determined the efficacy of DR7 against URTI in both young and middle-aged adult populations.

Nasal symptoms and the number of URTI occurrences were reduced in the DR7 group compared with the placebo group, accompanied by reduced plasma proinflammatory cytokines such as TNF- $\alpha$ and IFN- $\gamma$ and increased plasma anti-inflammatory cytokines such as IL-10 and IL-4 in the DR7 group compared with the placebo group. Upon separation of subjects based on age, DR7 benefited middle-aged adults more than young adults, primarily via action against proinflammatory cytokines, while DR7 improved URTI of young adults by increasing anti-inflammatory cytokines. Such anti-inflammatory properties also correlated with reduced plasma TBA levels and increased ferric reducing antioxidant potential levels in RBC, indicating reduced peroxidation and oxidative stress upon administration of DR7. The DR7 isolate benefited both the young and middle-aged adult populations primarily by decreasing plasma TBA levels. Based on the requirement of power design, our sample size was calculated according to a difference of $1 \mathrm{~d}$ in sickness duration between the treatment and placebo groups (Tiollier et al., 2007). Although we achieved only 109 subjects when the power design required 112 subjects (additional of 10\% dropout, thus totaling 124 subjects), all parameters studied (nasal, pharyngeal, general flu) showed more than $1 \mathrm{~d}$ of difference between DR7 and placebo groups during the 12 -wk intervention period, indicating compliance on statistical power.

Because inflammation and oxidative parameters are associated with immunity, immune parameters were investigated. We postulated that DR7 would benefit 


\section{L. plantarum DR7 alleviated URTI via}

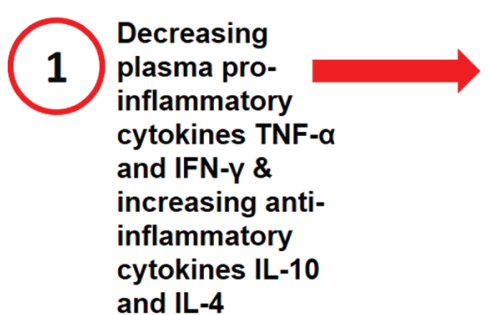

TBA levels \&

FRAP levels

cytokines IL-10

and IL-4

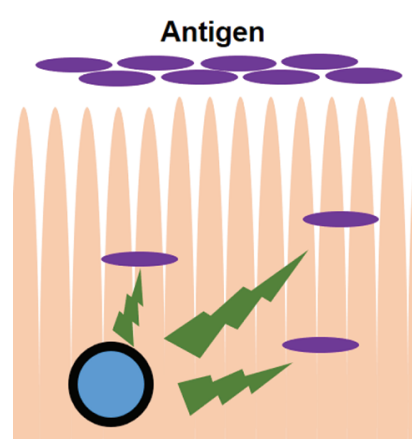

Actions of NK cells to eliminate antigens
2

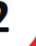

plasma

peroxidation

antioxidative

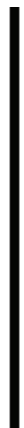

Enhancing mucosal epithelial integrity leading to reduced infiltration of antigen
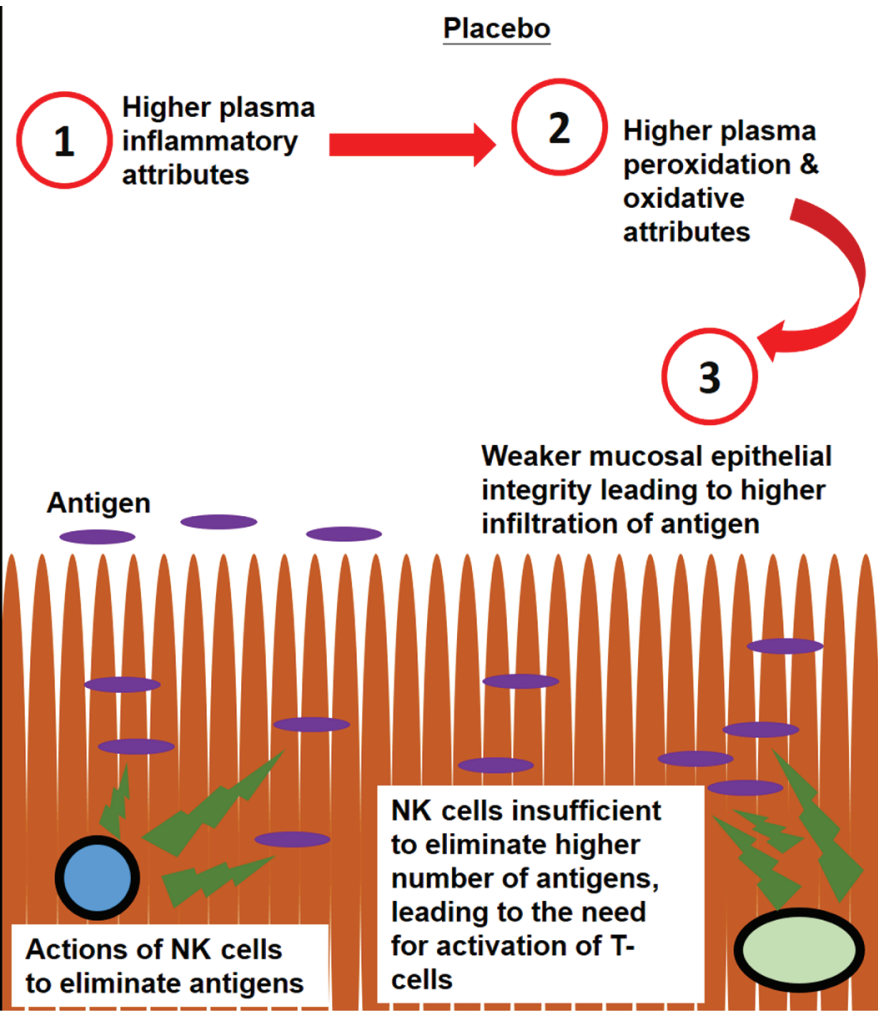

Figure 7. Postulated mechanisms of actions by Lactobacillus plantarum DR7 against upper respiratory tract infection (URTI); DR7 reduced nasal symptoms and number of occurrences for incidences of URTI primarily via management of inflammatory properties such as (1) decreasing plasma proinflammatory cytokines [tumor necrosis factor (TNF)- $\alpha$, IFN- $\gamma$ ] and increasing anti-inflammatory cytokines (IL-10, IL-4), (2) reducing plasma peroxidation [thiobarbituric acid (TBA) levels] and increasing red blood cell (RBC) antioxidative (ferric-reducing antioxidant potential (FRAP) levels] properties. In addition, DR7 enhanced mucosal epithelial integrity, leading to lower infiltration of antigens (3). The actions of natural killer (NK) cells as the first line defense of innate immunity against antigens were sufficient, leading to the reduced needs for activation of adaptive immunity $\mathrm{T}$ cells. However, these anti-inflammatory and oxidative properties were not enhanced in placebo subjects, leading to weaker mucosal epithelial integrity and higher infiltration of antigens. These factors led to increased need for activation of both NK cells and T cells.

immunity parameters by enhancing the mucosal barrier against the invasion of pathogens. Many factors can affect gut barrier functions, including disruptions of cholesterol metabolism. An increased accumulation of cholesterol in the liver and intestinal cells has been found to disrupt cholesterol and bile acid metabolism leading to gut barrier compromise, disruption, and inflammation (Banerjee et al., 2016). We have previously reported that DR7 exhibited the ability to prevent accumulation of cholesterol in liver and intestinal cell lines (Lew et al., 2018). Our present study also showed that immunity parameters were activated in the placebo group, while subjects receiving DR7 did not show changes. Pathogens may penetrate the intestinal mucosal barrier via various mechanisms such as phagocytosis of antigen-presenting cells or through direct invasion into the intestinal epithelial. The DR7 isolate has exhibited antimicrobial properties against selective pathogens, while other strains of Lactobacillus have been reported to protect the integrity of the mucosal barrier by inhibiting the adhesion of pathogens (Bron et al., 2017), attenuating pathogen-induced changes of the mucosal barrier (Yu et al., 2013, 2015), or stimulating local epithelial innate immune responses to restore epithelial barrier functions (Pagnini et al., 2010). The placebo group of middle-aged adults showed increased gene expression of $\mathrm{CD} 4$ and $\mathrm{CD} 8$, while the placebo group of young adults showed decreased expression of CD44 and CD117 compared with the DR7 group. Expression of CD4 and CD8 is increased while the expression of CD44 and CD117 is decreased in mature T cells and upon activation by antigens (Ceredig and Rolink, 2002), indicating that subjects receiving the placebo had a higher infiltration of antigens leading to the need for activation of $\mathrm{T}$ cells compared with those receiving DR7. Meanwhile, the placebo group showed increased gene expression of CD56, CD94, NKp46, and NKp30 compared with the DR7 group. Decreased expression of CD56, CD94, and NKp46 is observed at the final stages of development for NK cells (Yu et al., 2013), while increased expression of NKp30 indicates NK cells at a resting stage (Pallmer and Oxenius, 2016). Our data 
indicated that subjects in the DR7 group had higher nonresting and late-stage development of NK cells compared with the placebo group. Because NK cells are one of the first immune defense barriers for innate immunity, while T-cells play crucial roles in adaptive immunity (Vivier et al., 2011), we postulate that DR7 alleviated URTI via activation of NK cells against antigens that successfully infiltrated mucosal membrane integrity. Considering that the infiltration of antigens was lower in the DR7 group compared with the placebo group, we postulate that the actions of innate immunity NK cells were sufficient, and thus adaptive immunity $\mathrm{T}$ cells were less activated (Figure 7).

Altogether, our present study showed that although DR7 exhibited different effects in young and middleaged adult populations, this probiotic generally exerted protective roles against URTI primarily via enhancing immunomodulatory and anti-inflammatory functions. Although DR7 showed higher effects in suppressing proinflammatory cytokines in middle-aged adults, an enhancement of anti-inflammatory cytokines was observed in young adults upon administration of DR7; both actions led to reduced plasma peroxidation and oxidative stress. Although DR7 was associated with higher expression of plasma CD44 and CD117 in young adults, lower expression of plasma CD4 and CD8 was observed in middle-aged adults upon administration of DR7; both indicated the presence of less activated T cells, accompanied by the presence of nonresting and mature NK cells.

\section{CONCLUSIONS}

Our present study showed that the administration of DR7 (9 log cfu) daily for 12 wk had various effects against URTI. We postulate that DR7 can protect adult populations against URTI by inducing immunomodulatory and anti-inflammatory effects while promoting mucosal barrier integrity and actions of NK cells.

\section{ACKNOWLEDGMENTS}

Prebiotics were obtained courtesy of Aqurate Ingredients Intl., Kuala Lumpur, Malaysia, and DR7 was obtained courtesy of Clinical Nutrition, Kuala Lumpur, Malaysia. Clinical Nutrition was the approved Industrial Sponsor. This work was supported by the 2016 Yeungnam University Research Grant. We thank the funder for providing ideas in the stages of designing the experiments and reading the manuscript for intellectual content prior to submission per our decision. All other authors are not affiliated with any sponsors of this study and declare no competing financial or conflict of interest. MTL, KLO, and YHP conceived and designed the experiments; HXC, NAAY, YYH, LCL, MHJ, SBC, and MSBY performed the study and analyzed the data; NW, MFILA, and NZ contributed clinical services; and HXC, YYH, LCL, MHJ, and MTL wrote the manuscript.

\section{REFERENCES}

Ahanchian, H., C. M. Jones, Y. S. Chen, and P. D. Sly. 2012. Respiratory viral infections in children with asthma: Do they matter and can we prevent them? BMC Pediatr. 12:147-153.

Banerjee, S., G. Sindberg, F. Wang, J. Meng, U. Sharma, L. Zhang, P. Dauer, C. Chen, J. Dalluge, T. Johnson, and S. Roy. 2016. Opioidinduced gut microbial disruption and bile dysregulation leads to gut barrier compromise and sustained systemic inflammation. Mucosal Immunol. 9:1418-1428.

Benzie, I. F., and J. J. Strain. 1996. The ferric reducing ability of plasma (FRAP) as a measure of "antioxidant power": The FRAP assay. Anal. Biochem. 15:70-76.

Bramley, T. J., D. Lerner, and M. Sarnes. 2002. Productivity losses related to the common cold. J. Occup. Environ. Med. 44:822-829.

Bron, P. A., M. Kleerebezem, R. J. Brummer, P. D. Cani, A. Mercenier, T. T. MacDonald, C. L. Garcia-Ródenas, and J. M. Wells. 2017. Can probiotics modulate human disease by impacting intestinal barrier function? Br. J. Nutr. 117:93-107.

Cairns, S., J. G. Thomas, S. J. Hooper, M. P. Wise, P. J. Frost, M. J. Wilson, M. A. Lewis, and D. W. Williams. 2011. Molecular analysis of microbial communities in endotracheal tube biofilms. PLoS One 6:e14759.

Carney, E. W., and R. Settivari. 2013. Predictive toxicology: Biological assay platforms. Pages 777-806 in A Comprehensive Guide to Toxicology in Preclinical Drug Development. A. S. Faqi, ed. Academic Press, Cambridge, UK.

Ceredig, R., and T. Rolink. 2002. A positive look at double-negative thymocytes. Nat. Rev. Immunol. 2:888-897.

FAO/WHO. 2001. Evaluation of health and nutritional properties of probiotics in food including powder milk with live lactic acid bacteria. Accessed August 2018. http://www.fao.org/3/a-a0512e.pdf.

FAO/WHO. 2006. Probiotics in Food: Health and Nutritional Properties and Guidelines for Evaluation. WHO, Rome, Italy.

Haywood, B. A., K. E. Black, D. Baker, J. McGarvey, P. Healey, and R. C. Brown. 2014. Probiotic supplementation reduces the duration and incidence of infections but not severity in elite rugby union players. J. Sci. Med. Sport 17:356-360.

Hor, Y. Y., L. C. Lew, A. S. Y. Lau, J. S. Ong, L. O. Chuah, Y. Y Lee, S. B. Choi, F. Rashid, N. Wahid, Z. Sun, L. Y. Kwok, H. Zhang, and M. T. Liong. 2018. Probiotic Lactobacillus casei Zhang (LCZ) alleviates respiratory, gastrointestinal \& RBC abnormality via immuno-modulatory, anti-inflammatory \& anti-oxidative actions. J. Funct. Foods 44:235-245.

Hor, Y. Y., and M. T. Liong. 2014. Use of extracellular extracts of lactic acid bacteria and bifidobacteria for the inhibition of dermatological pathogen Staphylococcus aureus. Zhonghua Pifuke Yixue Zazhi 32:141-147.

Huang, Z., H. Xie, V. Ioannidis, W. Held, H. Clevers, M. S. Sadim, and Z. Sun. 2006. Transcriptional regulation of CD4 gene expression by $\mathrm{T}$ cell factor-1/beta-catenin pathway. J. Immunol. 176:4880-4887.

Juhn, Y. J., D. Frey, X. Li, and R. Jacobson. 2012. Streptococcus pyogenes upper respiratory infection and atopic conditions other than asthma: A retrospective cohort study. Prim. Care Respir. J. 21:153-158.

Kashiwagi, K., J. Ishii, M. Sakaeda, Y. Arimasu, H. Shimoyamada, H. Sato, C. Miyata, H. Kamma, I. Aoki, and T. Yazawa. 2012. Differences of molecular expression mechanisms among neural cell adhesion molecule 1, synaptophysin, and chromogranin A in lung cancer cells. Pathol. Int. 62:232-245.

Klare, I., C. Konstabel, G. Werner, G. Huys, V. Vankerckhoven, G. Kahlmeter, B. Hildebrandt, S. Muller-Bertling, W. Witte, and 
H. Goossens. 2007. Antimicrobial susceptibilities of Lactobacillus, Pediococcus and Lactococcus human isolates and cultures intended for probiotic or nutritional use. J. Antimicrob. Chemother. 59:900-912.

Lacoma, A., M. Gomes-Fernandes, E. Mesalles, F. Arméstar, R. Villar, I. Casas, S. Molinos, M. Giménez, V. Ausina, and C. Prat. 2015. Persistence of Staphylococcus aureus in lower respiratory tract in patients undergoing mechanical ventilation. Eur. Respir. J. 46:2640-2645.

Lau, A. S., N. Yanagisawa, Y. Y. Hor, L. C. Lew, J. S. Ong, L. O. Chuah, Y. Y. Lee, S. B. Choi, F. Rashid, N. Wahid, H. Sugahara, J. Z. Xiao, and M. T. Liong. 2018a. Bifidobacterium longum BB536 alleviated upper respiratory illnesses and modulated gut microbiota profiles in Malaysian pre-school children. Benef. Microbes 9:61-70.

Lau, A. S. E., M. S. B. Yusoff, Y. Y. Lee, S. B. Choi, F. Rashid, N. Wahid, J. Z. Xiao, and M. T. Liong. 2017. Development, translation and validation of Malay questionnaires for diarrhea and respiratory-related illnesses during probiotic administration in children. Educ. Med. J. 9:19-30.

Lau, A. S. E., M. S. B. Yusoff, Y. Y. Lee, S. B. Choi, J. Z. Xiao, and M. T. Liong. 2018b. Development and validation of Chinese translated questionnaires: A single simultaneous tool for assessing gastrointestinal, upper respiratory tract related illnesses in pre-school children. J. Taibah Univ. Med. Sci. 13:135-141.

Lehtoranta, L., A. Pitkaranta, and R. Korpela. 2014. Probiotics in respiratory virus infections. Eur. J. Clin. Microbiol. Infect. Dis. 33:1289-1302.

Lew, L. C., R. Bhat, A. M. Easa, and M. T. Liong. 2011. Development of probiotic carriers using microbial transglutaminase-crosslinked soy protein isolate incorporated with agrowastes. J. Sci. Food Agric. 91:1406-1415.

Lew, L. C., S. B. Choi, B. Y. Khoo, and M. T. Liong. 2013. $\mathrm{Mn}^{2+}$ and $\mathrm{Mg}^{2+}$ improved sphingomyelinase production by Lactobacillus rhamnosus FTDC 8313 and binding affinity to sphingomyelin for generation of ceramides. Process Biochem. 48:1815-1821.

Lew, L. C., Y. Y. Hor, B. Y. Khoo, S. Sasidharan, and M. T. Liong. 2018. Lactobacillus plantarum DR7 reduces cholesterol via phosphorylation of AMPK that down-regulated the mRNA expression of HMGCR. Korean J. Food Sci. Anim. Resour. 38:350-361.

Lim, Y., S. Sivasampu, A. Hwong, B. Sim, and S. Chandrasekaran. 2013. Prescribing patterns and factors influencing the choice of antibiotics in upper respiratory tract infections in Malaysia. Accessed January 2019. http://www.crc.gov.my/nhsi/wp-content/ uploads/document/Prescribing\%20patterns\%20and\%20factors \%20influencing $\% 20$ the $\%$ 20choice $\% 20$ of\%20antibiotics $\% 20$ in $\% 20$ URTI.pdf

Lin, C. S., H. T. Lee, M. H. Lee, S. C. Pan, C. Y. Ke, A. W. Chiu, and Y. H. Wei. 2016. Role of mitochondrial DNA copy number alteration in human renal cell carcinoma. Int. J. Mol. Sci. 17(6):814. https://doi.org/10.3390/ijms17060814.
Lin, C. W., Y. H. Chen, Y. C. Chuang, T. Y. Liu, and S. M. Hsu. 2003. CD94 transcripts imply a better prognosis in nasal-type extranodal NK/T-cell lymphoma. Blood 102:2623-2631.

Ooi, L. G., R. Ahmad, K. H. Yuen, and M. T. Liong. 2010. Lactobacillus gasseri $\mathrm{CHO}-220$ and inulin reduced plasma total cholesterol and low-density lipoprotein cholesterol via alteration of lipid transporters. J. Dairy Sci. 93:5048-5058.

Pagnini, C., R. Saeed, G. Bamias, K. O. Arseneau, T. T. Pizarro, and F. Cominelli. 2010. Probiotics promote gut health through stimulation of epithelial innate immunity. Proc. Natl. Acad. Sci. USA 107:454-459.

Pallmer, K., and A. Oxenius. 2016. Recognition and regulation of $\mathrm{T}$ cells by NK cells. Front. Immunol. 7:251.

Pettigrew, M. M., J. F. Gent, K. Revai, J. A. Patel, and T. Chonmaitree. 2008. Microbial interactions during upper respiratory tract infections. Emerg. Infect. Dis. 14:1584-1591.

Rubió-Casadevall, J., J. L. Borràs, M. C. Carmona-García, A. Ameijide, A. Gonzalez-Vidal, M. R. Ortiz, R. Bosch, F. Riu, D. Parada E. Martí, J. Miró, J. J. Sirvent, J. Galceran, and R. Marcos-Gragera. 2015. Correlation between mutational status and survival and second cancer risk assessment in patients with gastrointestinal stromal tumors: A population-based study. World J. Surg. Oncol. $13: 47-53$.

Shemesh, A., A. Kugel, N. Steiner, M. Yezersky, D. Tirosh, A. Edri, O. Teltsh, B. Rosental, E. Sheiner, E. Rubin, K. S. Campbell, and A. Porgador. 2016. NKp44 and NKp30 splice variant profiles in decidua and tumor tissues: A comparative viewpoint. Oncotarget 7:70912-70923.

Tham, C. S. C., K. K. Peh, R. Bhat, and M. T. Liong. 2012. Probiotic properties of bifidobacteria and lactobacilli isolated from local dairy products. Ann. Microbiol. 62:1079-1087.

Tiollier, E., M. Chennaoui, D. Gomez-Merino, C. Dragou, E. Filaire, and C. Y. Guezennec. 2007. Effect of a probiotic supplementation on respiratory infections and immune and hormonal parameters during intense military training. Mil. Med. 172:1006-1011.

Tuo, Y. F., L. W. Zhang, and H. X. Yi. 2010. Short communication: Antiproliferative effect of wild Lactobacillus strains isolated from fermented foods on HT-29 cells. J. Dairy Sci. 93:2362-2366.

Uematsu, T., T. Fujita, H. J. Nakaoka, T. Hara, N. Kobayashi, Y. Murakami, M. Seiki, and T. Sakamoto. 2016. Mint3/Apba3 depletion ameliorates severe murine influenza pneumonia and macrophage cytokine production in response to the influenza virus. Sci. Rep. 6:37815

Vivier, E., D. H. Raulet, A. Moretta, M. A. Caligiuri, L. Zitvogel, L. L. Lanier, W. M. Yokoyama, and S. Ugolini. 2011. Innate or adaptive immunity? The example of natural killer cells. Science 331:44-49.

Yu, J., A. G. Freud, and M. A. Caligiuri. 2013. Location and cellular stages of NK cell development. Trends Immunol. 34:1-16.

Yu, Q., L. Yuan, J. Deng, and Q. Yang. 2015. Lactobacillus protects the integrity of intestinal epithelial barrier damaged by pathogenic bacteria. Front. Cell. Infect. Microbiol. 5:26. 